\title{
PROMESSAS, POLÍTICAS E INTERROGAÇÕES SOBRE AS IDENTIDADES DOS SUJEITOS DA EJA
}

\author{
Sandra Regina Sales \\ Universidade Federal Rural do Rio de Janeiro \\ Gustavo E. Fischman \\ Arizona State University, Estados Unidos
}

\begin{abstract}
Resumo
O campo da Educação de Jovens e Adultos (EJA), especialmente a partir da promulgação da Constituição Federal de 1988, se encontra tensionado entre grandes aspirações e promessas e significativas limitações cotidianas como a falta de implementação de políticas e práticas pedagógicas apropriadas ao público ao qual ela se destina. Se por um lado, parece evidente o consenso de parte da sociedade, expresso em textos legais, em torno da ideia de que a educação é um bem social que deve ser expandido a todos independentemente da idade, por outro lado, os debates sobre a idade certa, os processos de "migração perversa” que expulsam jovens das "escolas regulares” para a EJA e os posicionamentos que veem a heterogeneidade dos estudantes da EJA como um déficit, combinados com as políticas de fechamento de turmas, escolas e programas, além das limitações orçamentárias, fragilizam as oportunidades de aprender que deveriam sustentar a promessa da EJA. Neste texto interrogamos as políticas atuais, as promessas, as tensões conceituais e os debates sobre as identidades dos sujeitos da EJA não apenas para identificar problemas, mas, sobretudo, para encorajar um compromisso pedagógico de resistência às politicas de fragilização da EJA a partir do reconhecimento da interseccionalidade de seus sujeitos e da recuperação da noção de “esperança” Freireana.
\end{abstract}

Palavras-chave: Educação de Jovens e Adultos; políticas educacionais, identidades; interseccionalidade; esperança.

\begin{abstract}
The field of Youth and Adult Education (known as EJA in Portuguese), especially since the promulgation of the Federal Constitution of Brazil in 1988, is tensioned between great promising aspirations and significant limitations. While, social consensus, as expressed in legal texts, around the idea that education is a social right that should be expanded to all regardless of age, seems to be evident this promising recognition is far from being a reality in Brazil. Some of the most pressing challenges are expressed in debates about the "right age to enter in EJA", the processes of "perverse migration" that expel young people from "regular schools" to EJA and the understanding of the heterogeneity of EJA's students as a deficit. To these already challenging situation we need to highlight the budget constraints and closures of classes, schools and programs, policies that undermine opportunities for learning that should underpin EJA's promise. In this text, we interrogate current policies, their promises, conceptual tensions and debates about the identities of EJA's subjects not only to identify problems, but, above all, to encourage pedagogical commitments to resist the weakening of EJA's field from the vantage point of recognizing the intersectionality of its subjects and assisted by the Freirean notion of "hope".
\end{abstract}

Keywords: Youth and Adult Education; educational policies, identities; intersectionality; hope.

ISSN 1645-1384 (online) www.curriculosemfronteiras.org 
Quando uma escola pública se perde na incompetência, indiferença ou desespero, deveria ser um momento de luto, pois é a perda de um lugar de possibilidades. Quando a educação pública está ameaçada, como parece estar ameaçada neste momento pelo cinismo e afastamento, pelo frio interesse dos mercadores, por medidas frágeis de defesa da democracia e pela perda do espírito cívico - quando tudo isso acontece, precisamos evocar o que a escola poderia nos ensinar, expressar o que poderíamos aprender, reivindicar em voz alta nossos direitos e defender fortemente nossas convicções (ROSE, 1999, p. 433).

No campo da Educação de Jovens e Adultos (EJA) no Brasil não são incomuns debates que se articulam como uma série de tensões entre perspectivas que enfatizam a distância entre as promessas expressas na legislação e sua efetivação nos sistemas educativos. Também são frequentes discussões sobre a necessidade de desenhar políticas voltadas para atender aos problemas do analfabetismo e da baixa escolaridade no Brasil ou a contemplar a heterogeneidade tanto de contextos, quanto de identidades dos sujeitos. Se, por um lado, esses debates têm uma longa tradição (DI PIERRO, 2005; DI PIERRO, JOIA \& RIBEIRO, 2001; HADDAD \& DI PIERRO, 2000; OLIVEIRA, 1999), por outro lado é importante reconhecer que a partir do impeachment da presidenta do país ocorrido em 2016, se gera um novo cenário no qual a EJA é particularmente afetada.

Não cabe nesse texto desenvolver exaustivamente todas as mudanças políticas, econômicas, culturais e educacionais, mas no campo da EJA, é fundamental ressaltar o impacto nas vidas d@s estudantes e docentes das mudanças nas leis trabalhistas e da reforma da previdência; os ataques a @s professor@s e aos trabalhadores da cultura; as manifestações contrárias aos direitos dos povos indígenas, aos afro-brasileiros, à populações imigrantes em geral, aos grupos de Lésbicas, gays, bissexuais, mulheres travestis, mulheres e homens transexuais, de pessoas intersexuais e nãobinárias ou queer (LGBTI +) e às políticas de gênero; somado a isso, a Emenda Constitucional que limita o orçamento da educação e da saúde; o fechamento dos programas de EJA; a extinção da Secretaria de Educação Continuada, Alfabetização e Diversidade e Inclusão (SECADI); os ataques à obra de Paulo Freire que incluem propostas de retirar-lhe o título de Patrono da Educação. Afetando diretamente o acesso ao sistema, não pode ser omitida também a redução nas matrículas de EJA, que embora não seja uma política nova, tem se aprofundado nos últimos anos.

Sem dúvida, as dinâmicas mencionadas acima se refletem no cotidiano das aulas de EJA, como exemplificam as reflexões de Cláudia e Alan, dois professor@s do campo:

“É muito angustiante”, diz Claudia uma professora com muita experiência "Se ganha o PT é porque nós enganamos ao povo; se ganha a direita, a esquerda fala que a culpa e nossa, porque não conscientizamos... Ganhou a direita e hoje o governo nos acusa de Freireanos propagadores de ideologia de gênero e outras mentiras. Seria engraçado se não fosse tão triste ... eu não consigo me acostumar com isso de ser sempre culpados... Não importa o que façamos, na EJA sempre a culpa e nossa".

Alan entanto relembra que "Não havia noite de quinta ou sexta-feira em que percorria, na mesma estrada de barro, a distância entre o local em que conseguia deixar meu veículo em segurança e o prédio da Unidade Escolar (UE). Em meio a todas as dificuldades enfrentadas por nós educadores, o difícil acesso geográfico não nos causava tanto desconforto quanto a sensação de insegurança local.” (FERREIRA, 2018) 
Os sentimentos de insegurança, angústia e tristeza expressos nas palavras de Cláudia e Alan, somados às instabilidades geradas pelas mudanças nos planos econômicos e políticos poderiam ser generalizados a outros âmbitos do campo da educação, ${ }^{1}$ embora pareçam ser as persistentes marcas de identidade da EJA. ${ }^{2}$ Sem dúvida, estamos em uma situação crítica que precisa urgentemente de esforços que contribuam para refletir e agir coletivamente como forma de resistência aos ataques contra as estruturas e as pessoas envolvidas na EJA. Assim, o presente dossiê reúne trabalhos sobre as promessas, políticas e perguntas que interrogam as desigualdades, equidades e inclusões no campo da EJA. Interrogamos algumas dessas ideias que se expressam como tensões articuladas entre os espaços gerados nas restrições das políticas educativas; nos conflitos sobre as identidades dos sujeitos da EJA no que tange às desigualdades, equidades e inclusões; na ideia do potencial da educação ao longo da vida e nas propostas de intervenção para atender as especificidades nesse campo.

\section{Compreensões em tensão: sobre os sujeitos da EJA e seus direitos}

A afirmação do direito à educação de jovens e adultos em textos legais e acordos internacionais dos quais o Brasil é signatário ${ }^{3}$ revela um nível de consenso por parte da sociedade em torno da ideia de que a educação é um bem social que deve ser expandido a todos, independentemente da idade. É interessante destacar que na legislação atual esse direito é voltado para aqueles que "não tiveram acesso na idade própria" e que a educação obrigatória "na idade certa” é para as crianças e adolescentes entre 4 e 17 anos de idade, como preconiza a legislação educacional. Essa compreensão revela que no Brasil a EJA se destina a um público específico, jovens e adultos que não se enquadram na "norma" e que, por algum motivo, se desviaram da trajetória escolar tida como correta (SALES \& PAIVA, 2014).

Embora não neguemos a importância de tais textos legais, notamos que existe uma tensão entre a as aspirações expressas nas leis e acordos internacionais e a concretização dos direitos dos cidadãos jovens e adultos ao acesso e permanência no sistema educativo. Essa tensão evidencia uma série de limitações práticas que permeiam os sistemas educativos no Brasil, dentre elas a definição da idade para ingresso nos cursos e exames e a determinação da permanência ou exclusão de jovens da chamada escola "regular", dois aspectos que se reforçam mutuamente e geram grandes níveis de desconforto tanto para os profissionais como para @s estudantes e suas famílias.

A questão da idade para entrar na EJA vem sendo foco de intensos debates que se manifestam diretamente nos marcos legais (BRASIL, 2008; BRASIL, 2010). Um momento marcante desse debate foi a redução da indicação de idade - de 21 para 18 anos - para realização dos exames supletivos no Ensino Médio e, no Ensino Fundamental, de 18 para 15 anos, estabelecida na Lei de Diretrizes e Bases da Educação Nacional em 1996. ${ }^{4}$ Educadores e pesquisador@s da EJA reagiram negativamente, argumentando que a lógica que sustentou essa mudança respondia a uma ideia de "limpar o sistema” e acelerar o processo de escolarização por meio dos exames supletivos. Di Pierro, Joia \& Ribeiro (2001, p. 67-68) afirmam que

ao rebaixar a idade mínima para o acesso a essa forma de certificação de 18 para 15 anos no ensino fundamental e de 21 para 18 no ensino médio, sinalizou para as instâncias normativas estaduais a identificação cada vez maior entre o ensino supletivo e os mecanismos de aceleração do ensino regular, medida cada vez mais aplicada nos estados e municípios, visando à correção do fluxo no sistema. 
As dificuldades assinaladas acerca da EJA na Lei de Diretrizes e Bases da Educação Nacional (LDB) reemergem em 2008, quando o debate sobre a idade ganha novo fôlego a partir de proposta do Conselho Nacional de Educação que, por meio de um parecer, sugeriu ao Ministério da Educação (MEC) que encaminhasse mudança Constitucional visando a alteração da idade para ingresso no Ensino Fundamental e Médio na EJA para 18 anos. A referida proposta foi motivada pelo que se denominou no documento "migração perversa" para a EJA que estaria ocorrendo no país, (BRASIL, 2010) na medida em que "escolas regulares" estariam transferindo quase que compulsoriamente estudantes com 15 anos para a EJA e também não aceitando matrículas de estudantes com 15 anos ou mais, como afirma no texto que serviu de base para as audiências públicas que discutiram essas medidas, a professora Mayer (2008, p. 1):

a fixação de uma "idade ideal” para a conclusão da escolaridade universal obrigatória (14 anos para o Ensino Fundamental), ainda que não tivesse esta intenção, favoreceu que a população acima desta faixa etária fosse vista como "invasora” ou destituída do direito de freqüentar o Ensino Regular. É comum que adolescentes a partir de 15 anos e jovens adultos, ao procurarem escolas para ingressar ou retomar os estudos, sejam imediatamente encaminhados para EJA, sem que outras oportunidades de educação lhes sejam oferecidas, cristalizando o lugar comum, de que o Ensino Regular é para aqueles que se encontram na "idade ideal”, a idade da obrigatoriedade.

A proposta do Conselho Nacional de Educação de aumentar para 18 anos a idade de acesso a EJA nunca se materializou, mas ficou evidente no processo de debates instalado pelo MEC, especificamente nas audiências públicas realizadas em 2008, que o tema da idade mínima para ingresso na EJA não foi (BRASIL, 2010) e ainda está longe ser um consenso na área. Essa falta de consenso se percebe mais explicitamente quando o debate sobre a idade mínima de acesso a EJA se cruza com as questões da permanência ou da exclusão dos jovens que não são bem-vindos na chamada "escola regular” e, para muitos, nem na EJA. Ainda segundo Mayer (2008, p. 2):

Adolescentes têm visto na EJA, a oportunidade para "acelerar" seus estudos e a escola a possibilidade de "livrar-se" de alunos indisciplinados. Como conseqüência temos uma confusão quanto aos objetivos e finalidades da EJA, que passa a ser vista, exclusivamente, como uma forma de "acelerar”, de corrigir a “defasagem idade-série” dos/das adolescentes.

Com trajetórias marcadas por reprovações, por desistências ou, ainda, por problemas de indisciplina, muitos desses jovens atingem os 15 anos de idade sem sequer concluir seu processo de alfabetização e, na perspectiva de muitos gestores e professor@s, já não se enquadram mais nessa escola das crianças "na idade certa". Um dos argumentos presentes no debate sobre a “migração perversa” é inadequação do currículo que, na visão de Mayer (2008, p. 2),

(...) tem "empurrado” adolescentes com idade cada vez mais baixa, especialmente nas periferias dos grandes centros urbanos, para a EJA. São comuns os relatos de que adolescentes "indisciplinados" têm sido convidados a freqüentar a EJA, também quando não têm idade para a certificação. Nestes casos, tem sido sugerido que apenas freqüentem as aulas, aguardando a idade para certificação ou que esperem (fora da escola) até atingirem a idade preestabelecida. Quando “optam” por freqüentar a EJA, é comum que estudantes e seus familiares, indignados, acionem canais de reclamação e denúncia, exigindo a certificação de conclusão do curso, por diferentes motivos que vão da colocação no mercado de trabalho à imediata oportunidade de continuar estudos em nível superior. 
Outro aspecto que se deve contemplar em relação à "migração perversa" apontada pelo Conselho Nacional de Educação é que a oferta da EJA se organiza e se estrutura tradicionalmente em cursos noturnos. A oferta noturna foi conceitualizada desde uma perspectiva homogeneizadora dos sujeitos da EJA. Nessa concepção, tod@s@s usuários são adultos que trabalham em um horário também organizado no padrão tradicional, geralmente das 8h às17h, e para @s quais a escola noturna é a melhor alternativa. Embora muitos possam se beneficiar com esse formato tradicional, a realidade é bem mais heterogênea, como bem demonstra o artigo de Souza e Andrade neste dossiê. Na cotidianidade, muitas turmas da EJA têm que se confrontar com os novos regimes de emprego muitas vezes não compatíveis ao modelo de escola noturna. Além disso, e como o pequeno depoimento de Alan nos lembra, a violência urbana que muitas vezes afeta algumas das comunidades em que funcionam escolas que ofertam EJA, geram maior apreensão com respeito aos cursos noturnos entre as famílias,@s alun@se@s professor@s.

Muit@s pesquisadore@s e educadores do campo em questão reconhecem as limitações e vêm buscando superar o olhar homogeneizador sobre os sujeitos da EJA (SOARES, 2003; DI PIERRO, 2005; PAIVA \& SALES, 2013; SALES \& PAIVA, 2014). Esse olhar se caracteriza por reduzir as diferenças e a multiplicidade dos sujeitos da EJA a apenas uma qualidade ou característica, ignorando ou tornando secundárias outras dinâmicas identitárias. Muito frequentemente essa perspectiva se manifesta no enquadramento dos sujeitos exclusivamente como “estudantes” em relação de subordinação a outros papéis muito bem marcados na estrutura escolar, como o papel d@s docentes, gestores ou funcionários em geral. Nessa perspectiva, são pouco prováveis e não têm demasiado lugar outras dinâmicas e lógicas sociais, identitárias e culturais desses sujeitos, que têm suas identidades reduzidas à uma marca institucional.

Outra tendência, igualmente homogeneizadora, identifica o sujeito da EJA mais que estudante ou estudante trabalhador, como sendo trabalhador estudante, como indicam Franzoi, Fischer, Silva \& Barros (2019, p. 4): “Quanto ao estudante trabalhador, é fundamental considerar suas especificidades. Alguns autores chegam a propor que sejam chamados de trabalhadores estudantes, pois são antes trabalhadores do que estudantes”. Tal identificação se relaciona fundamentalmente com o fato de que os sujeitos da EJA pertencem à classe trabalhadora, aquela que, segundo a teoria Marxista, vive da sua força de trabalho, sendo por isso, subalternizada e explorada dentro do sistema capitalista. A referida perspectiva Marxista tem uma forte presença entre os docentes e pesquisadore@s e uma base estrutural fácil de reconhecer, já que o público real e potencial da EJA, as pessoas analfabetas ou pouco escolarizadas, pertencem em sua esmagadora maioria à classe trabalhadora e aos extratos mais empobrecidos da sociedade. Sem dúvida, o pertencimento de classe é relevante na constituição dos sujeitos da EJA, mas a identidade de qualquer sujeito não se limita à classe social ou à sua condição de estudante.

Outras identidades como as raciais, étnicas, etárias, de gênero, e características como as necessidades especiais e as capacidades de aprender podem ser igualmente ou ainda mais relevantes na configuração da subjetividade dos sujeitos e deveriam ser consideradas na formulação de políticas e práticas pedagógicas, como concordam e demandam todos os artigos que compõem este dossiê. Em boa medida estas ideias se nutrem, de maneira implícita, em alguns casos e mais explicita em outros, dos aportes conceituais e metodológicos das perspectivas interseccionais oportunos e necessários para atender o desafio pedagógico de reconhecer as múltiplas dinâmicas identitárias dos sujeitos da EJA. Como afirmam Tefera, Powers \& Fischman (2018, p. 08) 
A interseccionalidade é uma aspiração conceitual e um imperativo para os pesquisadores da educação. Incorporar a noção de interseccionalidade na pesquisa exige que nossos estudos procurem (a) explicar as maneiras pelas quais raça / etnia, classe, gênero, sexualidade, religião, cidadania, habilidade e idade, entre outros fatores, moldam a dinâmica estrutural do poder e da desigualdade nos espaços sociais identidades individuais (Carbado, Crenshaw, Mays \& Tomlinson, 2013; Collins, 2015); e (b) fortalecer a sinergia entre investigação crítica e prática. Pesquisador@s em educação precisam ir além das análises unidimensionais ou de eixo único que se concentram em uma categoria específica (por exemplo, raça, ou classe, ou gênero ou habilidade) ou que tratam outras categorias como subordinadas. Em vez disso, a interseccionalidade abre conceitos espaços para identificar as lacunas e silêncios das análises e abordagens de categoria única, bem como as relações mutuamente constitutivas entre as categorias”

Um dos aportes que queremos ressaltar da perspectiva interseccional é que o desafio de responder a heterogeneidade dos sujeitos da EJA tem que ir além do mero reconhecimento simbólico ou da enumeração dessas identidades sem que exista uma acomodação e modificação substancial dos currículos, práticas e oportunidades de aprender. Nesse sentido, nos parece oportuno ressaltar a importância e a necessidade de refletir muito mais compreensivamente e reconhecer como características constitutivas e não como um déficit a heterogeneidade dos sujeitos da EJA. Tal como Ian Hacking (1999) indica, a constituição da identidade dos sujeitos não é um processo "natural”, mas requer de dez processos dinâmicos:

1) contar; 2) quantificar; 3) criar normas; 4) estabelecer relações; 5) medicalizar; 6) biologizar; 7) genetizar; 8) tornar normal; 9) burocratizar; e 10) reclamar identidade. Ainda segundo o autor, os sete primeiros mecanismos se destinam ao descobrimento do sujeito, o oitavo é um mecanismo da prática ou da ação, o nono de administração e o décimo consiste na resistência do sujeito, que se reconhece como tal (SALES \& PAIVA, 2014, p. 3). ${ }^{5}$

Em um trabalho anterior (SALES \& PAIVA, 2014) afirmávamos que um dos avanços na compreensão acerca dos sujeitos da EJA no Brasil foi o reconhecimento de suas identidades individuais; de sua heterogeneidade; como portadores e produtores de conhecimentos; como destinatários de direitos sociais, especialmente o direito à educação. Apesar de todos esses inegáveis avanços

o mecanismo de resistência Hackiano não está em um momento de expansão ou de consolidação em relação à criação dos sujeitos da EJA, ou acontece muito timidamente. Nossa observação não implica um olhar pessimista sobre a população da EJA, porque temos muitas evidências de participação ativa em lutas e mobilizações desses sujeitos em prol da garantia do direito à educação de seus filhos ou da luta por escola para os seus filhos ou, ainda, em inúmeros conflitos que se ancoram em alguma das múltiplas dinâmicas correlacionadas, como na luta pelo trabalho, pelo emprego, por moradia, pela terra, pela sexualidade e outras (SALES \& PAIVA, 2014, p. 9).

Certamente, como afirmamos no início do artigo, o atual contexto brasileiro representa um momento qualitativamente diferente, de aprofundamento dos ataques aos direitos já conquistados e barreiras ainda maiores para aquelas questões que ainda não foram atendidas para os usuários da EJA e os grupos historicamente marginalizados do povo brasileiro em geral. Este contexto adverso requer um olhar diferente, maior criatividade, maior empatia, maior solidariedade, maior respeito as nossas diferenças e as nossas semelhanças. Requer, ainda, toda sorte de mobilizações não só nas ruas, mas também nas escolas, nas salas de aula e nas comunidades. Precisamos reafirmar 
Promessas, políticas e interrogações sobre as identidades dos sujeitos da EJA

nossa tarefa pedagógica de ensinar a ler e a escrever a palavra e o mundo, procurando oportunidades de autorreconhecimento e de colaboração na construção de processos de resistência.

\section{Conclusões: Podemos ter esperanças na EJA?}

Há quase 20 anos, Daniel Schuguresnky e John P. Myers (2001) em artigo muito debatido, usaram a história da Cinderela para refletir sobre a situação da EJA A personagem em questão foi pensada em dois sentidos: no primeiro, e mais direto para descrever o status marginal da educação de adultos no mundo da educação, eles refletiram que

Apesar de os esforços realizados pelas agências de educação de adultos da região durante a última década, e apesar das altas expectativas derivadas da Declaração de Jomtien, o campo foi marginalizado de instituições educacionais nacionais e internacionais, que concentraram a maior parte de seus recursos e inovações pedagógicas no sistema escolar (SCHUGURENSKY\& MYERS 2001, p. 542).

No segundo sentido, os autores usaram a metáfora da Cinderela para ilustrar o processo ativo d@s ator@s do campo da EJA de procurar definir uma identidade, uma agenda e suas prioridades. Notando que:

Embora esse processo traga sobre conflitos de identidade inevitáveis, estamos confiantes de que, como na Cinderela da história, o sapato desaparecido aparecerá no devido tempo. Para que isso aconteça, porém, é importante refletir coletivamente sobre os sucessos e fracassos do passado e realizar uma análise prospectiva criativa das tendências futuras” (SCHUGURENSKY\& MYERS 2001, p .542).

A realidade educacional da EJA no Brasil é triste, insegura e gera angústia -resultado de uma longa história de des/encontros pedagógicos e políticos (SALES, 2019). Na segunda década do século XXI o campo da EJA atravessa um contexto de grandes dificuldades com recortes orçamentários, diminuição de serviços, falta de consensos sobre o que fazer nos acirrados debates cheios de posições ideologicamente férreas sobre o papel da educação na formação cidadã e laboral, e questões sobre sexualidade, religiosidade, democracia e justiça social. Nesse contexto parece que a educação, em geral, e a EJA, em particular, seria uma tarefa se não impossível, sem dúvida de um nível de dificuldade muito alto, tal como Kant há mais de 300 anos advertia.: "Existem duas invenções humanas que podem ser consideradas mais difíceis que quaisquer outras,' advertiu Kant, 'a arte de governar e a arte de educar'; e as pessoas continuam disputando os significados últimos dessas artes”. ${ }^{6}$

Para qualquer pessoa com algum grau de familiaridade com o sistema, a EJA surge hoje não apenas como alvo de severas críticas sociais, mas também como um dos últimos espaços de esperança, uma fronteira que demarca o ponto crucial entre a possibilidade de alcançar os sonhos da sociedade ou o fracasso em sustentar estas aspirações. Neste ponto crucial do imaginário social sobre a EJA, os sistemas se tornam artífices da esperança no futuro. Diante disso, como é possível reconciliar o grande número de críticas aos docentes da EJA com essa dose de esperança? Ainda mais, quão realista é manter a esperança na EJA como um pivô para realizar as funções reparadora, 
equalizadora e qualificadora estabelecidas no parecer 11/2000 do Conselho Nacional de Educação?

Uma boa parte d@s docentes, estudantes e pesquisador@s da EJA parece seguir o ditado que diz “a esperança é a última que morre”. Até Paulo Freire elevou o conceito de esperança à categorização de uma forma progressista de pedagogia. Mas novamente outras questões permanecem e, dentre elas, que tipo de esperanças são permitidas nestes tempos de governos neoliberais, conservadores e autoritários? "Apenas esperança”, entretanto e conforme veementemente declarado por Freire (1997a, p. 9), “é esperança em vão”. Para Freire e muitos dos estudios@s que seguiram o seu pedido de reinventá-lo e não copiá-lo, esperança é uma necessidade histórica e ontológica e não uma característica externa da situação pedagógica ou algo estranho à luta diária de professor@s e alun@s. Como tal, apenas quando a esperança é colocada em uma forma concreta, como uma experiência concreta de luta, como produto de diálogo e conflito, ela atinge seus objetivos. Freire (1997b, p. 69) afirma:

A esperança é um ímpeto natural, possível no contexto de nossa incompletude. A esperança é um tempo indispensável na nossa experiência humana e histórica. Sem ela, em lugar de história teríamos puro determinismo. A história existe apenas quando os tempos são problematizados e não simplesmente dados. Um futuro inexorável é uma negação da história.

Compreender o contexto atual de ataque e desmonte da EJA requer não apenas uma atitude esperançosa, mas também repensar as categorias de análise sem saudosismo, mas valorizando os ganhos parciais, os avanços e recuos, as limitações e também esses atos de coragem pedagógicos, muitas vezes inesperados e que nos dão grandes alegrias. Talvez então, esperança em tempos de populismos conservadores globalizados signifique que docentes, pesquisador@s e estudantes não têm outra possibilidade a não ser reconhecer pequenas e grandes lutas cotidianas da EJA para reclamar que se efetivem os direitos prometidos e uma educação que amplie as oportunidades de aprendizagens significativas, reafirmando suas identidades, respeitando as diferenças e construindo solidariedades interseccionais. É responsabilidade de cada participante da EJA reivindicar seus direitos e, especificamente nossa como professor@s e pesquisador@s, imaginar formas frutíferas de ensinar, de identificar as áreas de risco e de promover espaços para a esperança nestes tempos tristes nos quais as nossas ações individuais e coletivas podem mais uma vez demonstrar que a história está sempre por se fazer.

\section{Referências}

BARTRA, R. La jaula de la melancolía: identidad y metamorfosis del mexicano. Mexico - DF: Penguin Random House Grupo Editorial México, 2014.

BRASIL. Constituição da República Federativa do Brasil de 1988. DOU de 05 de outubro de 1988.

BRASIL. Lei No 9394 de 20 de dezembro de 1996. Diretrizes e Bases da Educação. DOU de 23 de dezembro de 1996.

BRASIL. Conselho Nacional de Educação. Parecer CNE/CEB n 23 de 2008. Institui Diretrizes Operacionais para a Educação de Jovens e Adultos. Aprovado em 08 de outubro de 2008.

BRASIL. Conselho Nacional de Educação. Resolução CNE/CEB n³de 2010. Dispõe sobre Diretrizes Operacionais para a Educação de Jovens e Adultos. DOU de 09 de junho de 2010.

DI PIERRO, M. C. Notas sobre a redefinição da identidade e das políticas de EJA no Brasil. Educação e Sociedade. Campinas, v. 26, n. 92, p. 1115-1139, Especial, 2005.

DI PIERRO, M. C.; JOIA, O. \& RIBEIRO, V. M. Visões da Educação de Jovens e Adultos no Brasil. Cadernos Cedes, ano XXI, n. 55, 2001. 
Promessas, políticas e interrogações sobre as identidades dos sujeitos da EJA

DONALD, J. Sentimental Education: Schooling Popular Culture and the Regulation of Liberty. London: Verso, 1992.

FERREIRA, A. S. Cartografias “outras” na EJA: por uma prática decolonial no Ensino de Geografia. Dissertação (Mestrado em Educação, Contextos Contemporâneos e Demandas Populares) - Universidade Federal Rural do Rio de Janeiro. Programa de Pós-Graduação em Educação, Contextos Contemporâneos e Demandas Populares, 2018.

FRANZOI, N. L., FISCHER, M. C. B., SILVA, C. O. B., \& BARROS, A. B. M. de. O estudante trabalhador na escola pública: Um direito negado? Arquivos Analíticos de Políticas Educativas, n. 27, v. 136, 2019. Disponível em: https://doi.org/10.14507/epaa.27.4068.

FREIRE, P. Pedagogy of the Heart. New York: Continuum, 1997a.

FREIRE, P. Pedagogy of Hope: Reliving the Pedagogy of the Oppressed. New York: Continuum, $1997 \mathrm{~b}$.

HADDAD, S. \& DI PIERRO, M. C. Escolarização de Jovens e Adultos. Revista Brasileira de Educação. maio/jun./jul./ago., p. 108-130, 2000.

HACKING, I. Making up people. The science studies reader, v. 18, p. 590-598, 1999.

MAYER, I. S. Idade para EJA. Conselho Nacional de Educação - Câmara de Educação Básica: Audiências sobre a Reformulação da Resolução CNE/CBE 1/00 - Educação de Jovens e Adultos - EJA. 2008. Disponível em: http://forumeja.org.br/?q=node/925. Acesso em: 29 out. 2019.

OLIVEIRA, M. K. Jovens e adultos como sujeitos de conhecimento e aprendizagem. Revista Brasileira de Educação, n. 12, 1999.

PAIVA, J. \& SALES, S. R. Contextos, perguntas, respostas: o que há de novo na educação de jovens e adultos? Arquivos Analíticos de Políticas Educativas . V. 21, n. 69, 2013. Disponível em: http://epaa.asu.edu/ojs/article/view/1456. Dossiê Educação de Jovens e Adultos; Editoras convidadas: Sandra Regina Sales \& Jane Paiva.

ROSE, N. Powers of freedom: Reframing political thought. Cambridge University Press, 1999.

SALES, S. R. (Org.) (Des)encontros na Educação de Jovens e Adultos: identidades, políticas e práticas. 1. ed. Curitiba: Editora CRV, 2019.

SALES, S. R. \& PAIVA, J. As muitas invenções da EJA. Arquivos Analíticos de Políticas Educativas, v. 22, n. 58, 2014. Disponível em: http://dx.doi.org/10.14507/epaa.v22n58. Dossiê Educação de Jovens e Adultos. Editoras convidadas: Sandra Regina Sales \& Jane Paiva.

SCHUGURENSKY, D. \& MYERS, J. P. Cinderella and the search for the missing shoe: Latin American adult education policy and practice during the 1990s, Journal of Education Policy, v. 16, n. 6, p. 527-546, 2001, DOI: 10.1080/02680930110087807.

\footnotetext{
${ }^{1}$ Talvez a desesperança seja uma marca social generalizada, como propõe Roger Bartra em seu livro “La melancolía moderna” ao afirmar que o desespero e a tristeza dos novos tempos estão relacionados ao mau funcionamento da democracia e fazem com que muitos se imaginem rejeitando a política em bloco, porque a consideram essencialmente corrupta ou maligna.

${ }^{2}$ Pouca coisa parece haver mudado desde que o educador popular Garcia Huidobro (1994) observou que a educação de adultos na América Latina é um empreendimento de baixo status, uma 'educação pobre para pessoas pobres' (apud SCHUGURENSKY\& MYERS 2001, p. 528).

${ }^{3}$ Como destaca Paiva no artigo deste dossiê 'Imaginando uma EJA que atenda a demandas de cidadania, equidade, inclusão e diversidade', a educação para os jovens e adultos se constitui um direito assegurado na Constituição Federal, na Lei de Diretrizes e Bases da Educação Nacional e também em acordos internacionais como nas Declarações de Conferências Internacionais sobre Educação de Adultos.

${ }^{4}$ Cabe aqui destacar que a referida Lei quando dispõe sobre a idade de ingresso na EJA o faz em relação aos exames supletivos, mas que tal referência se estendeu também à EJA presencial.

${ }^{5}$ Estas ideias se inspiram e dialogam com o trabalho de Ian Hacking (1999) em seu trabalho Modelando pessoas (em inglês Making Up People).

${ }^{6}$ A ideia de Kant foi retomada por Sigmund Freud. No último texto que escreveu, Freud reconheceu, com pesar, como havia feito em várias ocasiões prévias, os limites e frustrações de seu trabalho: "Parece que a análise era a terceira destas profissões
} 
'impossíveis’ nas quais alguém pode estar certo de antemão de que os resultados serão insatisfatórios. As outras duas conhecidas há muito mais tempo, são a educação e o governo.” (DONALD, 1992, p. 1). 


\section{Correspondência}

Sandra Regina Sales: Professora da Universidade Federal Rural do Rio de Janeiro.

E-mail: sandrasales@ufrrj.br

Gustavo E. Fischman: Professor da Arizona State University.

E-mail: fischman@asu.edu

Texto publicado em Currículo sem Fronteiras com autorização dos autores. 